\title{
Heatstroke and rhabdomyolysis presenting as fulminant hepatic failure
}

\author{
Sarah Fidler, ${ }^{1}$ Elizabeth Fagan, ${ }^{1}$ Roger Williams, ${ }^{1}$ I. Dewhurst ${ }^{2}$ and \\ C.E. Cory ${ }^{3}$
}

${ }^{1}$ The Liver Unit, King's College Hospital, Denmark Hill, London SE5 8RX, ${ }^{2}$ RAF Cranwell, Cranwell, Lincs NG34 8RN and ${ }^{3}$ Grantham \& Kesteven Hospital, Grantham, Lincs NG31 8DG, UK.

\begin{abstract}
Summary: Heatstroke following vigorous exercise is reported in a young male. Severe hepatic and renal failure resulted but the patient completely recovered following treatment by active measures to reduce his core temperature.
\end{abstract}

\section{Introduction}

Heatstroke associated with rigorous exercise is well documented especially during initial training ${ }^{1}$ and biochemical evidence of renal impairment and hepatic dysfunction including abnormal levels of blood urea, serum aspartate aminotransferase (AST) and hyperbilirubinaemia are commonly detected. ${ }^{1,2}$ The occurrence of established renal failure is rare, being reported in $4 \%$ of severe cases and is usually found with accompanying rhabdomyolysis. ${ }^{1-4}$ Only a few instances of severe hepatic necrosis and liver failure have been reported, usually in association with renal failure, and have a very poor prognosis. ${ }^{4}$

In the present report we describe a patient with heatstroke following vigorous exercise. $\mathrm{He}$, in addition, developed massive hepatic necrosis and fulminant hepatic failure as well as renal impairment and muscle injury. Active measures to reduce his core temperature were followed by complete recovery.

\section{Case report}

A 23 year old male Royal Air Force cadet suddenly collapsed whilst he was on his first training run which involved running for four miles in physical training kit in high summer. On admission to hospital his core temperature was $40.6^{\circ} \mathrm{C}$, rising to $41.6^{\circ} \mathrm{C}$ one hour later. He was disorientated and mildly jaundiced with evidence of marked bruising, muscle tenderness and pitting oedema of all limbs and abdominal wall. The initial blood pressure was

Correspondence: Roger Williams M.D., F.R.C.P.

Accepted: 3 September 1987
$180 / 70 \mathrm{mmHg}$, pulse $160 / \mathrm{min}$. An electrocardiogram showed a sinus tachycardia. On admission his haemoglobin was $13.5 \mathrm{~g} / \mathrm{dl}$, packed cell volume (PCV) 38.4, total white blood cell count (WBC) $11.7 \times 10^{9} / 1$, platelets $43 \times 10^{9} / 1$, fibrinogen degradation products (FDPs) $>1: 128$. Serum $\mathrm{K}^{+}$ $4.1 \mathrm{mmol} / 1, \mathrm{Na}^{+} 145 \mathrm{mmol} / 1, \mathrm{HCO}_{3}, 20 \mathrm{mmol} / 1$, urea $6.3 \mathrm{mmol} / \mathrm{l}$, creatinine $173 \mu \mathrm{mol} / 1$, glucose $3.5 \mathrm{mmol} / 1, \mathrm{pH} 7.4, \mathrm{PCO}_{2} 3.6 \mathrm{kPa}, \mathrm{PO}_{2} 12.8 \mathrm{kPa}$. AST $380 \mathrm{IU} / 1$, bilirubin $23 \mu \mathrm{mol} / 1, \quad$ alkaline phosphatase $166 \mathrm{IU} / 1$, prothrombin 5 seconds prolonged, creatinine kinase $>10,000$, urinalysis: positive for haemoglobin, myoglobin, urobilinogen and bilirubin. Attempts to lower his temperature with tepid sponging, electric fans and packing in ice were unsuccessful. He was therefore treated with intravenous chlorpromazine $12.5 \mathrm{mg}$ every $15 \mathrm{~min}$, fentanyl and pancuronium prior to ventilation which reduced the core temperature to $38.8^{\circ} \mathrm{C}, 6$ hours later. Over the ensuing 4 days he remained pyrexial $\left(37.7-38.9^{\circ} \mathrm{C}\right.$ core), hypertensive with a wide pulse pressure $(190-200 \mathrm{~mm} \mathrm{Hg}$, systolic/70$90 \mathrm{~mm} \mathrm{Hg}$ diastolic pressure) and remained confused despite treatment with chlorpromazine $5 \mathrm{mg} / \mathrm{h}$, maintained ventilation, continuous cooling and fluid replacement. The jaundice deepened (Figure 1) with further elevation of serum AST and alkaline phosphatase. The prothrombin time became 40 seconds prolonged by day 2 and peaked at 67 seconds prolonged by day 3 . On transfer to King's College Hospital (day 4), his hypertension and disorientation, attributed to cerebral oedema, responded to bolus doses $(2 \times 100 \mathrm{ml})$ of $20 \%$ mannitol over 24 hours and a subsequent diuresis. The chlorpromazine was discontinued on day 4 after the prothrombin time had begun to fall and by day 8 , the platelet count had risen to

(C) The Fellowship of Postgraduate Medicine, 1988 


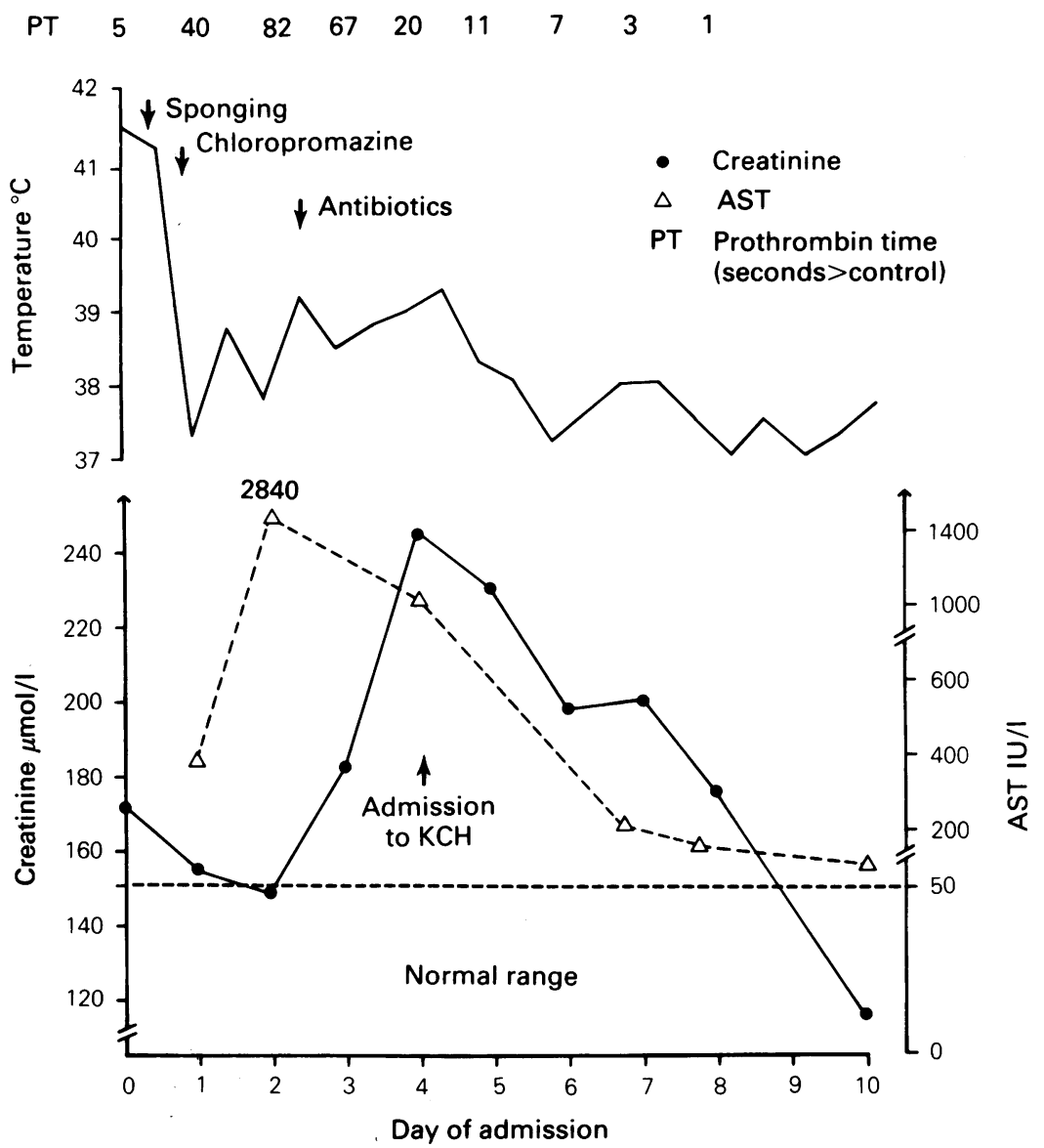

Figure 1

$157 \times 10^{9} / 1$. His clinical condition improved rapidly and he was discharged from hospital on the 14th day of illness with complete clinical and biochemical resolution of liver and renal damage.

\section{Discussion}

Survival from heatstroke after this degree of hepatic and renal failure must be very uncommon, particularly in association with marked rhabdomyolysis. ${ }^{1-4}$ The rise in serum AST and creatinine could be attributed partly to a skeletal muscle component but the progressive elevation in prothrombin time was indicative of severe hepatic dysfunction. Some degree of disseminated intravascular coagulation was apparent from the fall in platelet count and elevation in FDPs although these changes are also common in fulminant hepatic failure. ${ }^{5}$
The confusion may have been related, at least early on, to the heatstroke. Later, his disorientation was probably confounded by the hepatic encephalopathy since his mental state rapidly improved with treatment for cerebral oedema. Sustained systolic hypertension is not a feature of heatstroke per se but, in the context of this case, was more typical of cerebral oedema in association with fulminant hepatic failure ${ }^{6}$ and characteristically responded to administration of mannitol.

Rapid, effective cooling in heatstroke is mandatory but the optimal method remains controversial. Packing in ice may have been detrimental by effectively insulating the patient's core and hence delaying the temperature drop. Control of muscle hyperactivity to limit further generation of heat by paralysis with nondepolarising agents and chlorpromazine was almost certainly life-saving but required 4-5 days to be effective. 


\section{References}

1. Shibolet, S., Coll, R., Gilat, T. \& Sohar, E. Heatstroke: its clinical picture and mechanism in 36 cases. $Q \mathrm{~J} \mathrm{Med}$ 1967, 36: 525-548.

2. O'Donnell, T.F. Acute heatstroke. Epidemiologic, biochemical, renal and coagulation studies. JAMA 1975, 234: 824-828.

3. Olson, K.R. \& Benowitz, N.L. Environmental and drug-induced hyperthermia. Pathophysiology, recognition and management. Emerg Med Clin North Am 1984, 2: 459-474.
4. Kim, R.C., Collins, G.H., Cho, C., Ichikawa, K. \& Givelber, H. Heat stroke: report on three fatal cases with emphasis on findings in skeletal muscle. Arch Pathol Lab Med 1980, 104: 345-349.

5. Kew, M., Bersohn, I., Seftel, H. \& Kent, G. Liver damage in heatstroke. Am J Med 1970, 49: 192-201.

6. O'Grady, J.G., Langley, P.G., Isola, L.M., Aledort, L.M. \& Williams, R. Coagulopathy of fulminant hepatic failure. Semin Liver Dis 1986, 6: 159-163. 